\title{
Interactions between cigarette smoking and $X P C$-PAT genetic polymorphism enhance bladder cancer risk
}

\author{
YANG LIU ${ }^{1}$, HUANHUAN WANG ${ }^{2}$, TIANXIN LIN ${ }^{3}$, QUANFANG WEI ${ }^{2}$, \\ YI ZHI $^{1}$, FANG YUAN ${ }^{1}$, BO SONG ${ }^{1}$, JIN YANG $^{2}$ and ZHIWEN CHEN ${ }^{1}$ \\ ${ }^{1}$ Urology Institute of PLA, Southwest Cancer Center, Southwest Hospital and ${ }^{2}$ Department of Cell Biology, \\ Third Military Medical University, Chongqing 400038; ${ }^{3}$ Department of Urology, Sun Yat-sen \\ Memorial Hospital, Sun Yat-sen University, Guangzhou, Guangdong 510120, P.R. China
}

Received January 9, 2012; Accepted February 20, 2012

DOI: $10.3892 /$ or.2012.1759

\begin{abstract}
Inherited polymorphisms in the $X P C$ gene that lead to a reduction in DNA repair capacity may increase susceptibility to bladder cancer. We investigated three polymorphisms of the XPC gene (PAT, Ala499Val and Lys939GIn) in 600 subjects with bladder cancer and in 609 healthy controls by a polymerase chain reaction-restriction fragment length polymorphism (PCR-RFLP) assay in a Chinese Han population. Smoking was associated with a significant increase in the risk for bladder cancer (OR, 2.48; 95\% CI, 1.91-3.21). The risk was greater among heavy smokers (OR, 3.09, 95\% CI, 2.24-4.25) compared to light smokers (OR, 1.91, 95\% CI, 1.37-2.68). In three polymorphisms of $X P C$, only the $X P C$-PAT variant genotype exhibited a significantly increased risk for bladder cancer. When the total smoking exposure-gene interaction was examined, the three polymorphisms did not exhibit any significant effect in never smokers but a significant dose-response association in light or heavy smokers. Especially, the bladder cancer risk was significantly elevated among the polymorphisms of $X P C$-PAT ${ }^{(+-)}(\mathrm{OR}, 2.56,95 \% \mathrm{CI}, 1.56-4.21, \mathrm{P}<0.001$; OR, 3.41, 95\% CI, 2.19-5.29, $\mathrm{P}<0.001)$ and $X P C-\mathrm{PAT}^{(+/+)}(\mathrm{OR}$, 3. 00, 95\% CI, 1.31-6.88, P=0.009; OR, 6. 78, 95\% CI, 3.00$15.54, \mathrm{P}<0.001)$ with either light or heavy smoking exposure, respectively. $X P C$-PAT polymorphisms contribute to the risk for developing bladder cancer and an elevated risk of bladder cancer was significantly associated with the gene-environment (smoking) interaction in a Chinese Han population.
\end{abstract}

Correspondence to: Dr Zhiwen Chen, Urology Institute of PLA, Southwest Cancer Center, Southwest Hospital, Third Military Medical University, Chongqing 400038, P.R. China

E-mail: zhiwen@tmmu.edu.cn

Dr Jin Yang, Department of Cell Biology, Third Military Medical University, 30 Gao Tan Yan, Chongqing 400038, P.R. China

E-mail: jinyang@tmmu.edu.cn

Key words: bladder cancer, Chinese population, xeroderma pigmentosum complementary group $\mathrm{C}$, smoking, polymorphism

\section{Introduction}

Epidemiological studies suggest that cigarette smoking is strongly associated with the risk of bladder carcinoma $(1,2)$. Cigarette smoking accounts for approximately $65 \%$ of the bladder cancer risk in men and of 20-30\% in women. As there are thousands of carcinogens in cigarettes, it is not reasonable to attempt to discern out each molecular mechanism that corresponds to each carcinogen. But it has been previously demonstrated that these carcinogens cause DNA damage through the introduction of bulky adducts, crosslinks, and single or double-stranded breaks (3). The association between DNA damage and the increased cancer risk has been confirmed by numerous basic and epidemiological studies (4-7).

It has long been observed that individuals with seemingly equal exposure to cigarette smoking exhibit a great difference in the risk for developing bladder cancer. Men of Polynesian ancestry, including native Hawaiians, exhibit a high rate of smoking but a low incidence of bladder cancer (8). These findings suggest that there is potentially wide variability in an individual's response to cigarette smoking which could potentially be linked to genetic factors and interactions with cigarette smoking.

DNA damage repair is the primary defense mechanism against mutagenic exposure. There are four major DNA-repair pathways in human cells: nucleotide excision repair(NER), base excision repair (BER), mismatch repair (MMR), and doublestrand break (DSB) repair (9). The NER pathway principally removes bulky DNA adducts that are typically generated by exposure to the polycyclic aromatic hydrocarbons of tobacco smoke. There are currently over 100 known DNA repair genes, and most are known to display genetic variation in humans (10). Due to the presence of single-nucleotide polymorphisms (SNPs) in repair gene DNA, the functional properties of repair enzymes are changed or the level of transcription or translation is altered, all of which, in turn, reduce the capacity for DNA repair and induce genetic instability and carcinogenesis.

Xeroderma pigmentosum complementation group $\mathrm{C}$ $(X P C)$ is a component of the NER pathway $(11,12)$. It plays an important role in the early steps of global genome NER, particularly as a damage sensor in open complex formation as well as in the repair of complex protein formations $(13,14)$. 
Interestingly, emerging evidence suggests an additional role for XPC concerning removal of oxidative damage (15) and regulation of the cell cycle for DNA damage response (16). Mutations in this gene result in Xeroderma pigmentosum, a rare autosomal recessive disorder characterized by increased sensitivity to sunlight and the development of skin cancer at an early age (17). Previous studies have demonstrated that $X P C$ defective mice are highly prone to skin cancer following exposure to UV radiation and also are susceptible to common cancers, such as lung, esophageal, and bladder cancer when exposed to chemical carcinogens (18). These findings indicate that XPC may play a role in the prevention of human carcinogenesis. The two most common non-synonymous single nucleotide polymorphisms (SNPs), Lys939Gln (rs2228001) in exon 15 and Ala499Val (rs2228000) in exon 8, and a poly (AT) insertion/deletion polymorphism in intron 9 , have been associated with an increased risk of many human malignancies $(19,20)$.

However, recent molecular epidemiological studies in various populations have found an inconsistent association between $X P C$ polymorphisms and an increased risk for bladder cancer (20-22). Little is known about the interactions between $X P C$ polymorphisms and total smoking exposure (pack-years) on bladder carcinoma risk.

In the present case-control study in a Chinese Han population, we examined bladder cancer risk in relation to three polymorphisms of the $X P C$ gene and cigarette smoking as measured by smoking status and total exposure (pack-years). Additionally, we assessed whether the interactions between the $X P C$ gene polymorphisms and the total smoking exposure (pack-years) contributed to increased bladder cancer susceptibility.

\section{Materials and methods}

Study subjects. The patients who participated in this study were recruited from The Southwest Hospital in Chongqing, China and The Memorial Hospital of Sun Yat-sen University in Guangzhou, China. All patients resided locally, had incident, pathologically confirmed transitional cell carcinoma of the bladder, and were enrolled between January 1, 2007 and February 28, 2011. Patients with the following risk factors were excluded from the study: tumors of other origin metastasized to the bladder, previous radiotherapy, previous chemotherapy, and recurrent bladder cancer. Of 625 eligible cases during the study period, 600 participated (96\%). All controls were recruited from healthy subjects who were seeking routine health checkups in outpatient clinics at one of the two participating hospitals. The control subjects were frequency-matched to case subjects by age ( \pm 5 years), gender, and location of residence. Control subjects with: i) tumors; ii) family history of cancer; iii) blood transfusion in the past several months; iv) hematuria; or v) severe disease were excluded. All study participants were Han Chinese and lived in the study area continuously for $>15$ years, or for $>30$ years in total with no $>5$ years spent in another region.

Subjects who had never smoked or smoked $<100$ cigarettes over their lifetime were defined as never smokers; otherwise, they were considered as smokers (including former smokers and current smokers). A former smoker was defined as a person who quit smoking one year or more before the reference date (i.e., the date of diagnosis for study cases, the date of interview for controls). A current smoker was defined as someone still smoking or who had quit within one year of the reference date. We also conducted pack-year calculations to indicate the cumulative smoking dose [pack-years $=$ (cigarettes per day/20) x (years smoked)]. Light and heavy smokers were categorized using the median pack-year value of the controls as the cut-off point.

The cases were staged according to the 2002 International Union Against Cancer (UICC) tumor-nodes-metastasis classification and graded according to the World Health Organization 1973 grading of urothelial papilloma: welldifferentiated (grade 1, G1), moderately differentiated (grade 2, G2), or poorly differentiated (grade 3, G3).

In total, this study included 600 patients and 609 healthy controls. Written informed consent was obtained from all patients and controls participating in this study. Age, gender, and smoking status were recorded for all patients and controls. This study was approved by the local ethics committees of the two participating institutes.

Genotyping. Blood samples from each subject were collected in tubes containing ethylenediaminetetra-acetic acid (EDTA) and stored at $4^{\circ} \mathrm{C}$ until performance of genomic DNA extraction with TIANamp Genomic DNA kit (Tiangen Biotech Co., Ltd., Beijing, China). The XPC Ala499Val polymorphism was detected using primer-introduced restriction analysis (PIRA)-PCR (23). The PCR fragment was amplified using 5'-TAAGGACCCAAGCTTGCCㅌG-3' (forward, mismatched base is underlined) and 5'-CCCACT TTTCCTCCTGCTCACAG-3' (reverse) primers. The sense primer introduced a mismatched $\mathrm{C}$ to replace $\mathrm{A}$ at $-2 \mathrm{bp}$ from the polymorphic site (GenBank no. AF261898) to create a SacII restriction site. The SacII restriction enzyme (New England Biolabs, Beverly, MA) was used to distinguish the Ala499Val polymorphism $(\mathrm{C}>\mathrm{T})$. The $\mathrm{CC}$ genotype produced two fragments of 131 and $21 \mathrm{bp}$, whereas the TT genotype produced a single 152-bp fragment; the CT genotype contained all three bands (Fig. 1A). The PCR primers for XPC-PAT were 5'-TAGCACCCAGCAGTCAAAG-3' (forward) and 5'-TGTGAATGTGCTTAATGCTG-3' (reverse). The PCR products contained an intron 9 polymorphism of $X P C$ [an $83 \mathrm{bp}$ poly(AT) insertion with a 5-bp deletion of GTAAC]. $\mathrm{PAT}^{-/}$(wild-type) exhibited a 266-bp fragment, whereas $\mathrm{PAT}^{+/+}$(polymorphic type) exhibited a $344 \mathrm{bp}$ fragment, and $\mathrm{PAT}^{+/-}$(heterozygous type) contained both fragments (Fig. 1B). Genotyping of Lys939Gln of XPC was performed using the polymerase chain reaction restriction fragment length polymorphism (PCR-RFLP) technique. The PCR fragment generated was amplified using 5'-GGAGGTGGACTCTCTTCTGATG-3' (forward) and 5'-TAGATCCCAGCAGATGACC-3' (reverse) primers. The restriction enzyme $P v u$ II (New England Biolabs) was used to differentiate the Lys allele from the Gln allele. The subsequent fragment sizes were as follows: the Gln allele, which is recognized by $P v u \mathrm{II}$, resulted in 180 and 585-bp bands, whereas the uncut Lys allele resulted in a band at 765-bp; the heterozygote contained all three bands (Fig. 1C). We amplified $100 \mathrm{ng}$ of extracted blood DNA in a PCR reaction containing 10X PCR buffer (100 mM Tris-HCl, pH 8.3 and 

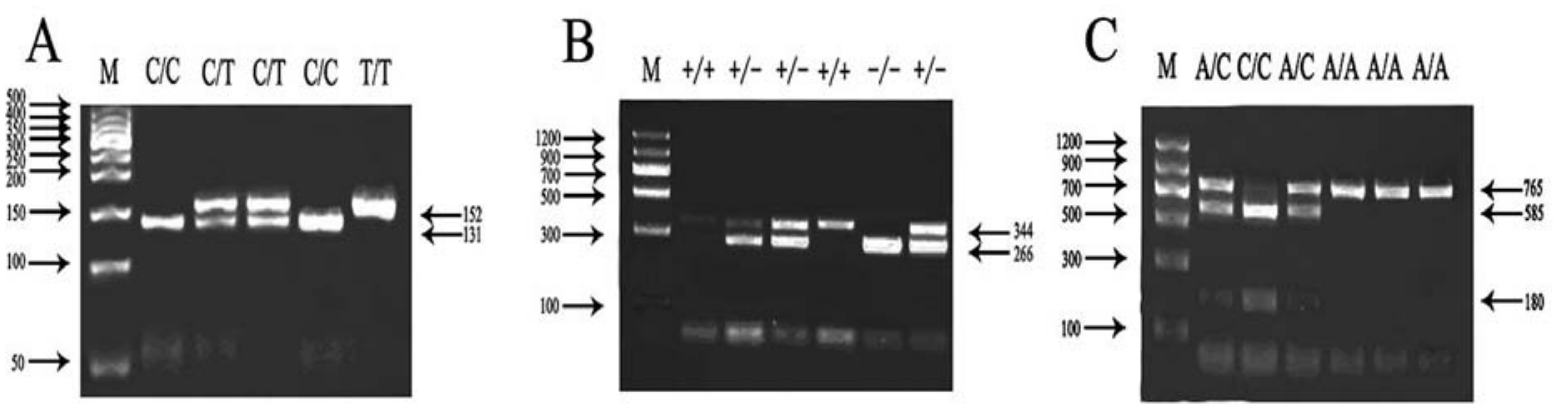

Figure 1. (A) PIRA-PCR method for detection of the C/T exon 8 polymorphism (XPC Ala499Val). SacII cuts the CC genotype into fragments of 131 bp and $21 \mathrm{bp}$, whereas the TT genotype produced a single 152-bp fragment; the CT genotype contained all three bands. The 21-bp fragment has run into the buffer. (B) PCR products of XPC-PAT alleles. PCR generated two fragments: a $344 \mathrm{bp} \mathrm{XPC-PAT}{ }^{+}$fragment and a $266 \mathrm{bp} \mathrm{XPC-PAT}$ fragment, permitting detection of

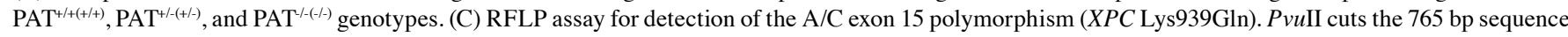
generated by PCR into fragments of 180 and 585 bp if the $\mathrm{C}$ allele is present in the sequence, permitting detection of $\mathrm{C} / \mathrm{C}, \mathrm{C} / \mathrm{A}$, and $\mathrm{A} / \mathrm{A}$ genotypes. M, DNA size marker.

$500 \mathrm{mM} \mathrm{KCl}) 5 \mu \mathrm{l}, 25 \mathrm{mM} \mathrm{MgCl} 23 \mu \mathrm{l}$, dNTP mixture (each $2.5 \mathrm{mM}) 4 \mu \mathrm{l}, 200 \mathrm{nM}$ of each primer and $5 \mathrm{U} / \mu \mathrm{l}$ Takara Taq $0.25 \mu \mathrm{l}$ (Takara Taq code: DR001A) in a final volume of $25 \mu 1$. PCR products were digested with the appropriate restriction endonucleases (New England Biolabs) that recognized and cut either the wild-type or variant sequences. The digested PCR products were separated by electrophoresis on $2-4 \%$ agarose gel and stained with ethidium bromide for visualization under ultraviolet (UV) light. The polymorphism analysis was performed by two analysts independently in a blinded manner. To confirm the genotype determined by PCR, $10 \%$ of the PCR-amplified DNA samples were randomly selected for direct DNA sequencing (Invitrogen, Shanghai, China); the results were $100 \%$ in concordance (data not shown).

Statistical analysis. The statistical Package for the Social Sciences (SPSS) software (version 13.0, SPSS Inc., Chicago, IL) was used for data analysis. The Student's t-test was performed to evaluate the difference in age between cases and controls. The differences between cases and controls for selected demographic characteristics, including gender and smoking status, were evaluated using the Chi-square $\left(\chi^{2}\right)$ test. Prior to analysis of the disease risk association, we used the Hardy-Weinberg equilibrium (HWE) to test the genotype and allele frequency by a goodness-of-fit $\chi^{2}$ test, with one degree of freedom (df) to compare the observed and expected genotype frequencies among cases and controls. To identify the appropriate genetic model, we examined 3 possible models (additive, dominant, and recessive) using a logistic regression model and differing genotype coding methods. The $\chi^{2}$ analysis was used to compare the genotype frequency between patients and controls. Multivariate logistic regression analysis adjusting for age, gender, and smoking status (pack-years) was used to estimate the association between each genotype and the risk of bladder cancer by computing the adjusted odds ratio and the $95 \%$ confidence interval. The genotype data were further stratified by cumulative smoking dose, tumor stage, and tumor grade, and identified using the statistical method mentioned above. The homozygous and heterozygous carriers of the polymorphisms were classified as a polymorphic genotype and combined for the purposes of statistical analysis due to the small number of the homo- zygous polymorphisms. To assess bladder cancer risk, the interactions between the XPC gene polymorphisms and smoking were analyzed using logistic regression, including main effect variables and their product terms. Two-sided tests of statistical significance were conducted, and a P-value of $<0.05$ was regarded as an indication of a statistically significant result.

\section{Results}

Characteristics of study subjects. A total of 600 cases and 609 controls were recruited for our study. The distribution of age and gender was comparable among cases and controls. However, the cases represented a significantly higher percentage of ever smokers $(52.7 \%)$ compared to controls $(35.1 \%)(\mathrm{P}<0.001)$, and a greater percentage of cases were heavy smokers $(31.0 \%)$ compared to controls $(17.1 \%)(\mathrm{P}<0.001)$. The demographic details of the study subjects and clinical characteristics of the cases are summarized in Table I.

Genetic models of three polymorphisms in the Chinese Han population. The three common genetic models (additive, dominant and recessive) did not demonstrate an association between elevated bladder cancer risk and XPC Ala499Val and Lys939Gln polymorphisms (Table II). However, we found that the estimated OR $(95 \% \mathrm{CI})$ for XPC $\mathrm{PAT}^{+/-}$was 1.24 (1.05-1.46) $(\mathrm{P}=0.013), 1.30(1.03-1.65)(\mathrm{P}=0.026)$, and 1.37 (0.98-1.92) $(\mathrm{P}=0.068)$ for the additive, dominant, and recessive genetic models, respectively. These results indicate that $X P C$ $\mathrm{PAT}^{+/}$either directly exerts an effect, or the linked functional gene impacts the disease trait, most likely in an additive or dominant genetic manner.

Association of XPC polymorphisms and bladder cancer risk. The three polymorphisms of the $X P C$ gene were consistent with HWE $(\mathrm{P}>0.05)$ in both the case and control groups. Each polymorphism, the distribution of gene variants in cases and controls, $\chi^{2}, \mathrm{P}$-values, adjusted ORs, and $95 \%$ CIs for bladder cancer risk are provided in Table III. The XPC Ala499Val and Lys939Gln were not associated with the risk of bladder cancer. However, $\mathrm{PAT}^{+/+}$of $X P C$ was significantly associated with bladder cancer (OR 1.52; 95\% CI, 1.06-2.18; $\mathrm{P}=0.022)$ after 
Table I. Demographic characteristics of bladder cancer cases and controls.

\begin{tabular}{|c|c|c|c|}
\hline Characteristics & Cases $(n=600)$ & Controls $(n=609)$ & P-value \\
\hline \multicolumn{4}{|l|}{ Age (years) } \\
\hline Mean \pm SD & $61.8 \pm 13.5$ & $61.4 \pm 14.1$ & $0.620^{\mathrm{b}}$ \\
\hline \multicolumn{4}{|l|}{ Gender (\%) } \\
\hline Male & $476(79.3)$ & $487(80.0)$ & \multirow[t]{2}{*}{$0.784^{\mathrm{c}}$} \\
\hline Female & $124(20.7)$ & $122(20.0)$ & \\
\hline \multicolumn{4}{|l|}{ Smoking status } \\
\hline Never smokers & $284(47.3)$ & $395(64.9)$ & \multirow{3}{*}{$<0.001^{\mathrm{c}, \mathrm{d}}$} \\
\hline Ever smokers ${ }^{\mathrm{a}}$ & $316(52.7)$ & $214(35.1)$ & \\
\hline Former smokers & $117(19.5)$ & $69(11.3)$ & \\
\hline Current smokers & $199(33.2)$ & $145(23.8)$ & $<0.001^{\mathrm{c}, \mathrm{d}}$ \\
\hline \multicolumn{4}{|c|}{ Cumulative smoking dose pack-years } \\
\hline Never smokers & $284(47.3)$ & $395(64.9)$ & \multirow[t]{3}{*}{$<0.001^{\mathrm{c}, \mathrm{d}}$} \\
\hline Light smokers, $\leq 25$ & $130(21.7)$ & $110(18.1)$ & \\
\hline Heavy smokers, $>25$ & $186(31.0)$ & $104(17.1)$ & \\
\hline \multicolumn{4}{|l|}{ Tumor stage } \\
\hline Superficial (pTa-pT1) & $345(57.5)$ & & \\
\hline Invasive (pT2-pT4) & $215(35.8)$ & & \\
\hline Unknown & $40(6.7)$ & & \\
\hline \multicolumn{4}{|l|}{ Tumor grade } \\
\hline Grade 1 & $265(44.2)$ & & \\
\hline Grade 2 & $219(36.5)$ & & \\
\hline Grade 3 & $60(10.0)$ & & \\
\hline Unknown & $56(9.3)$ & & \\
\hline
\end{tabular}

${ }^{\mathrm{a}} \mathrm{A}$ subject was considered as former smoker if he had not smoked for the past 1 year; the other smokers were categorized as current smokers. $\mathrm{P}$-values obtained from ${ }^{\mathrm{b}}$ Student's t-test and ${ }^{\mathrm{c}}$ the $\chi^{2}$ test; ${ }^{\mathrm{d}} \mathrm{P}<0.05$.

Table II. Genetic models of three polymorphisms in the Chinese population.

\begin{tabular}{llccc}
\hline XPC polymorphism & Model & $\chi^{2}$ & P-value & OR $^{\mathrm{a}}(95 \% \mathrm{CI})$ \\
\hline Ala499Val & Additive & 1.44 & 0.231 & $1.12(0.93,1.34)$ \\
& Dominant & 1.24 & 0.266 & $1.14(0.90,1.44)$ \\
& Recessive & 0.55 & 0.458 & $1.16(0.78,1.72)$ \\
PAT & Additive & 6.19 & 0.013 & $1.24(1.05,1.46)$ \\
& Dominant & 4.98 & 0.026 & $1.30(1.03,1.65)$ \\
& Recessive & 3.32 & 0.068 & $1.37(0.98,1.92)$ \\
Lys939Gln & Additive & 1.20 & 0.274 & $1.10(0.93,1.30)$ \\
& Dominant & 0.14 & 0.705 & $1.05(0.83,1.32)$ \\
& Recessive & 2.69 & 0.101 & $1.33(0.95,1.86)$ \\
\hline
\end{tabular}

${ }^{a}$ Adjusted for age, gender and smoking (pack-years).

adjustments for age, gender, and smoking (pack-years). The combined genotype $\mathrm{PAT}^{+/+}$and $\mathrm{PAT}^{+/}$exhibited a significant 1.33 -fold increase in risk for bladder cancer (OR, $1.33 ; 95 \% \mathrm{CI}$ 1.05-1.68; $\mathrm{P}=0.017)$.
Allelic association analysis for the three polymorphisms indicated that the $\mathrm{PAT}^{+}$allele was significantly associated with bladder cancer (OR, 1.26, 95\% CI, 1.06-1.48, $\mathrm{P}=0.008)$. In contrast, XPC Ala499Val and Lys939Gln were 
Table III. Distribution of XPC gene polymorphisms among controls and cases.

\begin{tabular}{lcccc}
\hline & $\begin{array}{c}\text { Controls } \\
\text { Genotype }\end{array}$ & $\begin{array}{c}\text { Cases } \\
(\mathrm{n}=600)(\%)\end{array}$ & $\chi^{2}$ P-value & OR $^{\mathrm{a}}(95 \%$ CI $)$ \\
\hline XPC Ala499Val & & & \\
Ala/Ala & $272(44.7)$ & $242(40.3)$ & & 1.00 \\
Ala/Val & $285(46.8)$ & $294(49.0)$ & $1.13(0.88,1.44)$ \\
Val/Val & $52(8.5)$ & $64(10.7)$ & 0.216 & $1.24(0.82,1.88)$ \\
Ala/Val, Val/Val & $337(55.3)$ & $358(59.7)$ & 0.128 & $1.17(0.93,1.48)$ \\
XPC-PAT & & & & 0.345 \\
-/- & $288(47.3)$ & $242(40.3)$ & & 1.00 \\
$+/-$ & $248(40.7)$ & $266(44.3)$ & & $1.24(0.97,1.59)$ \\
$+/+$ & $73(12.0)$ & $92(15.3)$ & 0.034 & $1.52(1.06,2.18)$ \\
$+/-,+/+$ & $321(52.7)$ & $358(59.7)$ & 0.015 & $1.33(1.05,1.68)$ \\
$X P C$ Lys939Gln & & & & 0.090 \\
Lys/Lys & $253(41.5)$ & $236(39.3)$ & & 0.022 \\
Lys/Gln & $281(46.1)$ & $272(45.3)$ & & 0.017 \\
Gln/Gln & $75(12.3)$ & $92(15.3)$ & 0.301 & $0.98(0.76,1.25)$ \\
Lys/Gln, Gln/Gln & $356(58.5)$ & $364(60.7)$ & 0.434 & $1.31(0.91,1.88)$ \\
\hline
\end{tabular}

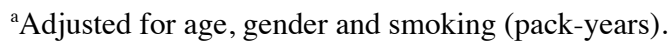

Table IV. Association of XPC gene polymorphisms with different clinical stage in bladder cancer cases.

\begin{tabular}{lcccc}
\hline Genotype & $\begin{array}{c}\text { Superficial } \\
(\mathrm{n}=345)(\%)\end{array}$ & $\begin{array}{c}\text { Invasive } \\
(\mathrm{n}=215)(\%)\end{array}$ & $\chi^{2}$ P-value & OR $^{\mathrm{a}}(95 \% \mathrm{CI})$ \\
\hline XPC Ala499Val & & & \\
Ala/Ala & $152(44.1)$ & $84(39.1)$ & & 1.00 \\
Ala/Val & $153(44.3)$ & $110(51.2)$ & & $1.30(0.90,1.87)$ \\
Val/Val & $40(11.6)$ & $21(9.8)$ & 0.287 & $0.93(0.51,1.70)$ \\
Ala/Val, Val/Val & $193(55.9)$ & $131(60.9)$ & 0.245 & $1.22(0.86,1.73)$ \\
XPC-PAT & & & & 0.164 \\
-/- & $144(41.7)$ & $86(40.0)$ & & 0.820 \\
+/- & $148(42.9)$ & $97(45.1)$ & & 1.00 \\
+/+ & $53(15.4)$ & $32(14.9)$ & 0.875 & $0.97(0.58,1.63)$ \\
$+/-,+/+$ & $201(58.3)$ & $129(60.0)$ & 0.684 & $1.02(0.72,1.45)$ \\
$X P C$ Lys939Gln & & & & 0.836 \\
Lys/Lys & $139(40.3)$ & $85(39.5)$ & & 0.915 \\
Lys/Gln & $155(44.9)$ & $96(44.7)$ & & 0.902 \\
Gln/Gln & $51(14.8)$ & $34(15.8)$ & 0.945 & $0.95(0.65,1.39)$ \\
Lys/Gln, Gln/Gln & $206(59.7)$ & $130(60.5)$ & 0.859 & $1.05(0.63,1.76)$ \\
\end{tabular}

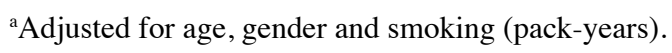

not associated with bladder cancer $(\mathrm{P}=0.093$ and $\mathrm{P}=0.182$, respectively).

Correlation of XPC polymorphisms with clinical parameters in bladder cancer patients. To determine the correlation between $X P C$ polymorphisms and clinical parameters, we classified bladder cancer patients as either exhibiting evidence of invasive (pT2-pT4) or superficial disease (pTa-pT1) (Table IV). Patients with different clinical grades were sub-categorized as low-risk (Grade 1) or high-risk (Grade 2-3) based on the 
Table V. Association of $X P C$ gene polymorphisms with different clinical grade in bladder cancer cases.

\begin{tabular}{|c|c|c|c|c|c|}
\hline Genotype & Low-risk $(\mathrm{n}=265)(\%)$ & High-risk $(\mathrm{n}=279)(\%)$ & $\chi^{2}$ P-value & $\mathrm{OR}^{\mathrm{a}}(95 \% \mathrm{CI})$ & P-value \\
\hline \multicolumn{6}{|l|}{ ХPC Ala499Val } \\
\hline Ala/Ala & $108(40.8)$ & $100(35.8)$ & & 1.00 & \\
\hline Ala/Val & $127(47.9)$ & $148(53.0)$ & & $1.19(0.82,1.73)$ & 0.354 \\
\hline $\mathrm{Val} / \mathrm{Val}$ & $30(11.3)$ & $31(11.1)$ & 0.456 & $1.08(0.60,1.94)$ & 0.803 \\
\hline Ala/Val, Val/Val & $157(59.2)$ & $179(64.2)$ & 0.239 & $1.17(0.82,1.67)$ & 0.388 \\
\hline \multicolumn{6}{|l|}{$X P C$-PAT } \\
\hline$-/-$ & $117(44.2)$ & $116(41.6)$ & & 1.00 & \\
\hline$+/-$ & $102(38.5)$ & $129(46.2)$ & & $1.19(0.82,1.74)$ & 0.364 \\
\hline$+/+$ & $46(17.4)$ & 34 (12.2) & 0.100 & $0.68(0.40,1.15)$ & 0.153 \\
\hline$+/-,+/+$ & $148(55.8)$ & $163(58.4)$ & 0.544 & $1.03(0.72,1.46)$ & 0.881 \\
\hline \multicolumn{6}{|l|}{ XPC Lys939Gln } \\
\hline Lys/Lys & $112(42.3)$ & $112(40.1)$ & & 1.00 & \\
\hline Lys/Gln & $109(41.1)$ & 133 (47.7) & & $1.15(0.78,1.67)$ & 0.485 \\
\hline $\mathrm{Gln} / \mathrm{Gln}$ & $44(16.6)$ & $34(12.2)$ & 0.192 & $0.71(0.42,1.20)$ & 0.202 \\
\hline Lys/Gln, Gln/Gln & $153(57.7)$ & $167(59.9)$ & 0.615 & $1.01(0.71,1.45)$ & 0.939 \\
\hline
\end{tabular}

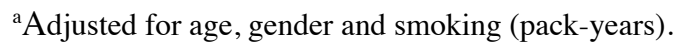

degree of differentiation (Table V). The three polymorphisms exhibited no statistically significant association with the pathological stages or grades.

Association of XPC gene polymorphism interaction with smoking and risk of bladder cancer. The environmental exposure of smoking, by itself, carries a risk of bladder cancer (Table VI). Ever smokers exhibited a higher risk of bladder cancer compared to never smokers (OR, 2.48, 95\% CI, 1.91-3.21). Among the ever smokers, risk estimates of bladder cancer were significantly higher for both heavy smokers (OR, 3.09, 95\% CI, 2.24-4.25) and light smokers (OR, 1.91, 95\% CI, 1.37-2.68) compared to never smokers. We also investigated the joint gene-environment interaction effects of the three polymorphisms and smoking relative to smoking status (never or ever) and total smoking exposure (never smoker, light smoker, and heavy smoker). In these analyses, the homozygous common allele/never smoker category was used as the reference. The interactions between genotype and total smoking exposure are presented in Table VI. The three polymorphisms exhibited no significant effect in never smokers. However, we found a significant dose-response correlation between the interaction of the three $X P C$ gene polymorphisms, the total smoking exposure and the risk of bladder cancer (Table VI). Subjects with the $\mathrm{PAT}^{+/+}$genotype who were exposed to light or heavy smoking demonstrated a higher risk for bladder cancer (OR, 3. 00, 95\% CI, 1.31-6.88, P=0.009; OR, 6. 78, 95\% CI, 3.00-15.54, $\mathrm{P}<0.001$, respectively).

\section{Discussion}

Accumulating evidence indicates that a reduced DNA repair capacity due to various DNA repair gene polymorphisms is associated with an increased risk for many human malignancies (24-27). In the current investigation, we examined the association of bladder cancer risk with variations in XPC and its interaction with subjects who smoke in a Chinese Han population. The data demonstrated that the subjects with the $X P C$-PAT polymorphism were at a significantly elevated risk for bladder cancer, suggesting that this polymorphism may contribute to the etiology of bladder cancer. Since cigarette smoking is a risk factor for bladder cancer we explored any possible gene and smoking interaction. We found a doseresponse association between the interactions of $X P C$ gene polymorphisms with total smoking exposure and the risk of bladder cancer. This study also revealed the direct association of the environmental contribution (smoking) with a higher genetic risk for bladder cancer.

Previous studies have investigated the effect of $X P C$ polymorphisms on bladder cancer risk. One previous report demonstrated that the XPC Ala499Val and Lys939Gin polymorphisms significantly elevated human bladder cancer risk in a Caucasian population (22) . In this study, we did not find XPC Ala499Val and Lys939Gin to be associated with an increased bladder cancer risk in a Chinese Han population. Our findings are in concordance with the results of a recent study of XPC polymorphisms in bladder cancer (28). However, our study clearly demonstrated that individuals carrying $\mathrm{PAT}^{+/+}$of XPC intron 9 were at a significantly increased risk for bladder cancer (OR, 1.52; 95\%, CI 1.06-2.18; $\mathrm{P}=0.022)$. The combined genotype $\mathrm{PAT}^{+/+}$and $\mathrm{PAT}^{+/-}$demonstrated a 1.33-fold increased risk associated with bladder cancer after adjustment for age, gender, and smoking status (pack-years) (OR, 1.33; 95\% CI, 1.05-1.68; $\mathrm{P}=0.017$ ). These findings are consistent with the results of a previous study of XPC $\mathrm{PAT}^{+/-}$ in bladder cancer in an Indian population (29). In contrast, 
Table VI. Association between the $X P C$ polymorphisms, smoking and the risk of bladder cancer.

\begin{tabular}{|c|c|c|c|c|c|}
\hline Variable & $\begin{array}{c}\text { Controls } \\
(\mathrm{n}=609)(\%)\end{array}$ & $\begin{array}{c}\text { Cases } \\
(n=600)(\%)\end{array}$ & $\chi^{2} \mathrm{P}$-value & $\mathrm{OR}^{\mathrm{a}}(95 \% \mathrm{CI})$ & P-value \\
\hline \multicolumn{6}{|l|}{ Smoking status } \\
\hline Never smokers & $395(64.9)$ & $284(47.3)$ & & 1.00 & \\
\hline Ever smokers & $214(35.1)$ & $316(52.7)$ & $<0.001$ & $2.48(1.91,3.21)$ & $<0.001$ \\
\hline Light smokers, $\leq 25$ pack-years & $110(18.1)$ & $130(21.7)$ & & $1.91(1.37,2.68)$ & $<0.001$ \\
\hline Heavy smokers, $>25$ pack-years & $104(17.1)$ & $186(31.0)$ & $<0.001$ & $3.09(2.24,4.25)$ & $<0.001$ \\
\hline Ala499Val and pack-years & & & $<0.001$ & & \\
\hline Ala/Ala and never smokers & $194(31.9)$ & $126(21.0)$ & & 1.00 & \\
\hline Ala/Val and never smokers & $176(28.9)$ & $134(22.3)$ & & $1.16(0.84,1.59)$ & 0.372 \\
\hline Val/Val and never smokers & $25(4.1)$ & $24(4.0)$ & & $1.50(0.82,2.75)$ & 0.194 \\
\hline Ala/Ala and light smokers & $28(4.6)$ & $40(6.7)$ & & $2.57(1.46,4.51)$ & 0.001 \\
\hline Ala/Val and light smokers & $67(11.0)$ & $76(12.7)$ & & $2.04(1.33,3.13)$ & 0.001 \\
\hline Val/Val and light smokers & $15(2.5)$ & $14(2.3)$ & & $1.70(0.78,3.69)$ & 0.182 \\
\hline Ala/Ala and heavy smokers & $50(8.2)$ & $76(12.7)$ & & $2.88(1.84,4.51)$ & $<0.001$ \\
\hline Ala/Val and heavy smokers & $42(6.9)$ & $84(14.0)$ & & $3.75(2.38,5.92)$ & $<0.001$ \\
\hline Val/Val and heavy smokers & $12(2.0)$ & $26(4.3)$ & & $4.09(1.97,8.52)$ & $<0.001$ \\
\hline PAT and pack-years & & & $<0.001$ & & \\
\hline $\mathrm{PAT}^{/-}$and never smokers & $182(29.9)$ & $122(20.3)$ & & 1.00 & \\
\hline $\mathrm{PAT}^{+/-}$and never smokers & $158(25.9)$ & $116(19.3)$ & & $1.13(0.81,1.58)$ & 0.486 \\
\hline $\mathrm{PAT}^{+/+}$and never smokers & $55(9.0)$ & $46(7.7)$ & & $1.22(0.77,1.93)$ & 0.402 \\
\hline $\mathrm{PAT}^{/-}$and light smokers & $61(10.0)$ & $56(9.3)$ & & $1.59(1.00,2.53)$ & 0.048 \\
\hline $\mathrm{PAT}^{+/-}$and light smokers & $39(6.4)$ & $57(9.5)$ & & $2.56(1.56,4.21)$ & $<0.001$ \\
\hline $\mathrm{PAT}^{+/+}$and light smokers & $10(1.6)$ & $17(2.8)$ & & $3.00(1.31,6.88)$ & 0.009 \\
\hline $\mathrm{PAT}^{/-}$and heavy smokers & $45(7.4)$ & $64(10.7)$ & & $2.67(1.67,4.27)$ & $<0.001$ \\
\hline $\mathrm{PAT}^{+/-}$and heavy smokers & $51(8.4)$ & $93(15.5)$ & & $3.41(2.19,5.29)$ & $<0.001$ \\
\hline $\mathrm{PAT}^{+/+}$and heavy smokers & $8(1.3)$ & $29(4.8)$ & & $6.78(3.00,15.54)$ & $<0.001$ \\
\hline Lys939GIn and pack-years & & & $<0.001$ & & \\
\hline Lys/Lys and never smokers & $163(26.8)$ & $127(21.2)$ & & 1.00 & \\
\hline Lys/Gln and never smokers & $177(29.1)$ & $111(18.5)$ & & $0.82(0.59,1.15)$ & 0.246 \\
\hline Gln/Gln and never smokers & $55(9.0)$ & $46(7.7)$ & & $1.05(0.66,1.66)$ & 0.842 \\
\hline Lys/Lys and light smokers & $52(8.5)$ & $50(8.3)$ & & $1.42(0.88,2.30)$ & 0.153 \\
\hline Lys/Gln and light smokers & $46(7.6)$ & $63(10.5)$ & & $2.05(1.27,3.30)$ & 0.003 \\
\hline Gln/Gln and light smokers & $12(2.0)$ & $17(2.8)$ & & $2.13(0.97,4.70)$ & 0.061 \\
\hline Lys/Lys and heavy smokers & $38(6.2)$ & $59(9.8)$ & & $2.49(1.52,4.07)$ & $<0.001$ \\
\hline Lys/Gln and heavy smokers & $58(9.5)$ & $98(16.3)$ & & $2.70(1.76,4.13)$ & $<0.001$ \\
\hline Gln/Gln and heavy smokers & $8(1.3)$ & $29(4.8)$ & & $5.79(2.53,13.28)$ & $<0.001$ \\
\hline
\end{tabular}

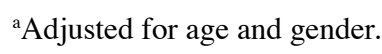

Zhu et al did not observe a significant association between XPC $\mathrm{PAT}^{+/-}$and bladder cancer risk in a Caucasian population (21). Ethnic variations may account for this diversity as the allele frequencies of the XPC $\mathrm{PAT}^{+/-}$polymorphism have been reported to vary dramatically between different ethnic groups. For example, $\mathrm{PAT}^{--},{ }^{+-}$, and ${ }^{+/+}$genotype frequencies were $47.3,40.7$, and $12.0 \%$, respectively, in the Han Chinese population in this study, compared with $38.1,45.9$, and $16.0 \%$, respectively, in the study of the Caucasian population (21).
These observations suggest that ethnic variations may modify the susceptibility of different ethnic groups.

It has been reported that PAT and the intron $11 \mathrm{C} / \mathrm{A}$ polymorphisms are closely associated due to linkage disequilibrium. The C/A polymorphism found at the -5 position of intron 11 is located at a splice acceptor site, and is associated with a deletion and skipping of exon 12. Interestingly, the exon 12 deleted $X P C$ mRNA isoform exhibits reduced DNA repair activity (30). Thus, the XPC-PAT polymorphism associated 
with bladder cancer risk may be caused by linkage disequilibrium with the intron $11 \mathrm{C} / \mathrm{A}$ polymorphisms.

Cigarette smoking is a well-established risk factor for bladder cancer $(31,32)$. As shown in Table VI, we found that cigarette smoking was associated with overall bladder cancer risk (OR, 2.48, 95\% CI, 1.91-3.21); the risk was greater among heavy smokers ( $>25$ pack-years of exposure) (OR, 3.09, 95\% CI, 2.24-4.25) compared to light smokers (OR, 1.91, 95\% CI, 1.37-2.68). However, there is wide variability in individual responses to cigarette smoking. For example, heavy smoking is considered a high risk factor for bladder cancer, but only a small percentage of heavy smokers develop this disease. This suggests that some people may be hypersusceptible, and that this is potentially associated with genetic factors. Recent molecular biological studies demonstrated that the risk of bladder cancer due to cigarette smoking is precisely linked to genetic markers that were detected using microarray analysis or the single-nucleotide polymorphism (SNP) method $(28,33,34)$.

Using logistic regression, we found a statistically significant increasing trend in smoking-related bladder cancer risk in correlation with the XPC-PAT polymorphisms (additive genetic model) among light smokers (OR, 1.59, 95\% CI, 1.00-2.53; OR, 2.56, 95\% CI, 1.56-4.21; and OR, 3.00, 95\% CI, 1.31-6.88, respectively) and heavy smokers (OR, 2.67, 95\% CI, 1.67-4.27; OR, 3.41, 95\% CI, 2.19-5.29; OR, 6.78, 95\% CI, 3.00-15.54, respectively). We did not observe significant associations between XPC Ala499Val or Lys939Gin polymorphisms and bladder cancer risk; however, when total smoking exposure was considered, bladder cancer risk was significantly elevated among XPC Ala499Val and Lys939Gln polymorphisms with light and heavy smoking exposure. Subjects homozygous for the XPC $939 \mathrm{Gln} / \mathrm{Gln}$ genotype exposed to light or heavy smoking demonstrated a higher risk for bladder cancer (OR, 2.13, 95\% CI, 0.97-4.70; OR, 5. 79, 95\% CI, 2.53-13.28, respectively). In never smokers, no association was found between the three polymorphisms of the $X P C$ gene and increased bladder cancer risk. These results suggest the existence of gene-smoking in modulating bladder cancer risk, and the effects of the XPC polymorphisms were highly dependent on total smoking exposure. The mechanisms underlying the observed gene-environment interaction remain to be elucidated. One could hypothesize that the polymorphisms of the $X P C$ gene affect the damage recognition of smoking-induced DNA bulky adducts, in turn leading to more unrepaired DNA damage and higher genomics mutagenesis.

The pathological grade reflected the degree of cancer cell differentiated in human bladder cancer. We did not find the three polymorphisms of the XPC gene to be associated with any of the clinical parameters we reviewed (clinical stage or grade) in bladder cancer patients. In bladder cancer it has been well-documented that the malignancy and progression are associated with multiple gene defects or mutations (35). Therefore, once the reduced DNA repair capacity leads to more oncogenes or tumor-suppressor gene mutations under effect of carcinogens from smoking, the accumulated different gene mutation may result in different tumor malignancies. Our previous investigation also indicated that the $X P C$ expression defect affected bladder cancer behavior dependent on p53 mutation $(16,36)$. We reason that the polymorphisms of the
$X P C$ gene may be an initial genetic event which interacts with carcinogens in bladder cancer carcinogenesis.

The principal limitation of this study is the relatively small sample size for gene-environment interaction assessment. Additional studies of these polymorphisms in different ethnic populations are necessary to confirm our results, and a larger sample size is warranted to investigate potentially relevant gene-environment interactions.

In conclusion, we demonstrated that the XPC-PAT polymorphism may contribute to the susceptibility to bladder cancer in the Chinese Han population. Importantly, gene-environment (total smoking exposure) interactions were associated with an elevated risk of bladder cancer. These results are based on a limited number of polymorphisms and a future study utilizing multiple study centers in a larger patient population is warranted.

\section{Acknowledgements}

The authors gratefully acknowledge the assistance of Ms. Xuemei Li, Yuanxiu Zhou, Jing Zhang, Ming Chen, Zhengyan $\mathrm{Li}$ and Lei Li in the collection of the samples, and Dr Mingkui Luo for assistance with the statistical analysis. Grants were obtained from the National Nature Science Foundation of China (no. 30972979, 30973385) and the National Basic Research Program of China ('973’ Program, no. 2010CB529402).

\section{References}

1. Baris D, Karagas MR, Verrill C, et al: A case-control study of smoking and bladder cancer risk: emergent patterns over time. J Natl Cancer Inst 101: 1553-1561, 2009.

2. Hirao Y, Kim WJ and Fujimoto K: Environmental factors promoting bladder cancer. Curr Opin Urol 19: 494-499, 2009.

3. IARC Working Group on the Evaluations of Carcinogenic Risks to Humans: Tobacco smoke and involuntary smoking. IARC Monogr Eval Carcinog Risks Hum 83: 1-1438, 2004.

4. Smith LE, Denissenko MF, Bennett WP, et al: Targeting of lung cancer mutational hotspots by polycyclic aromatic hydrocarbons. J Natl Cancer Inst 92: 803-811, 2000.

5. Yue W, Santen RJ, Wang JP, et al: Genotoxic metabolites of estradiol in breast: potential mechanism of estradiol induced carcinogenesis. J Steroid Biochem Mol Biol 86: 477-486, 2003.

6. Hussain SP, Schwank J, Staib F, Wang XW and Harris CC: TP53 mutations and hepatocellular carcinoma: insights into the etiology and pathogenesis of liver cancer. Oncogene 26: 2166-2176, 2007.

7. Upadhyay D and Kamp DW: Asbestos-induced pulmonary toxicity: role of DNA damage and apoptosis. Exp Biol Med (Maywood) 228: 650-659, 2003.

8. Foster F: New Zealand Cancer Registry report. Natl Cancer Inst Monogr 53: 77-80, 1979.

9. Wood RD, Mitchell M, Sgouros J and Lindahl T: Human DNA repair genes. Science 291: 1284-1289, 2001

10. Packer BR, Yeager M, Burdett L, et al: SNP500Cancer: a public resource for sequence validation, assay development, and frequency analysis for genetic variation in candidate genes. Nucleic Acids Res 34: D617-D621, 2006.

11. Sugasawa $\mathrm{K}, \mathrm{Ng} \mathrm{JM}$, Masutani C, et al: Xeroderma pigmentosum group $\mathrm{C}$ protein complex is the initiator of global genome nucleotide excision repair. Mol Cell 2: 223-232, 1998.

12. Min JH and Pavletich NP: Recognition of DNA damage by the Rad4 nucleotide excision repair protein. Nature 449: 570-575, 2007.

13. Thoma BS and Vasquez KM: Critical DNA damage recognition functions of XPC-hHR23B and XPA-RPA in nucleotide excision repair. Mol Carcinog 38: 1-13, 2003.

14. Tapias A, Auriol J, Forget D, et al: Ordered conformational changes in damaged DNA induced by nucleotide excision repair factors. J Biol Chem 279: 19074-19083, 2004. 
15. Brown KL, Roginskaya M, Zou Y, Altamirano A, Basu AK and Stone M: Binding of the human nucleotide excision repair proteins XPA and XPC/HR23B to the 5R-thymine glycol lesion and structure of the cis- $(5 \mathrm{R}, 6 \mathrm{~S})$ thymine glycol epimer in the 5'-GTgG-3' sequence: destabilization of two base pairs at the lesion site. Nucleic Acids Res 38: 428-440, 2010.

16. Chen Z, Yang J, Wang G, Song B, Li J and Xu Z: Attenuated expression of xeroderma pigmentosum group $\mathrm{C}$ is associated with critical events in human bladder cancer carcinogenesis and progression. Cancer Res 67: 4578-4585, 2007.

17. Kraemer KH, Lee MM, Andrews AD and Lambert WC: The role of sunlight and DNA repair in melanoma and nonmelanoma skin cancer. The xeroderma pigmentosum paradigm. Arch Dermatol 130: 1018-1021, 1994.

18. Sands AT, Abuin A, Sanchez A, Conti CJ and Bradley A: High susceptibility to ultraviolet-induced carcinogenesis in mice lacking XPC. Nature 377: 162-165, 1995.

19. Francisco G, Menezes PR, Eluf-Neto J and Chammas R: XPC polymorphisms play a role in tissue-specific carcinogenesis: a meta-analysis. Eur J Hum Genet 16: 724-734, 2008.

20. Qiu L, Wang Z and Shi X: Associations between XPC polymorphisms and risk of cancers: A meta-analysis. Eur J Cancer 44: 2241-2253, 2008

21. Zhu Y, Lai M, Yang H, et al: Genotypes, haplotypes and diplotypes of XPC and risk of bladder cancer. Carcinogenesis 28: 698-703, 2007.

22. de Verdier PJ, Sanyal S, Bermejo JL, Steineck G, Hemminki K and Kumar R: Genotypes, haplotypes and diplotypes of three XPC polymorphisms in urinary-bladder cancer patients. Mutat Res 694: 39-44, 2010.

23. Hu Z, Wang Y, Wang X, et al: DNA repair gene XPC genotypes/ haplotypes and risk of lung cancer in a Chinese population. Int J Cancer 115: 478-483, 2005.

24. Ribas G, Gonzalez-Neira A, Salas A, et al: Evaluating HapMap SNP data transferability in a large-scale genotyping project involving 175 cancer-associated genes. Hum Genet 118: 669-679, 2006.

25. Marin MS, Lopez-Cima MF, Garcia-Castro L, Pascual T, Marron MG and Tardon A: Poly (AT) polymorphism in intron 11 of the XPC DNA repair gene enhances the risk of lung cancer. Cancer Epidemiol Biomarkers Prev 13: 1788-1793, 2004.
26. Zhang L, Zhang Z and Yan W: Single nucleotide polymorphisms for DNA repair genes in breast cancer patients. Clin Chim Acta 359: 150-155, 2005.

27. Garcia-Closas M, Malats N, Real FX, et al: Genetic variation in the nucleotide excision repair pathway and bladder cancer risk. Cancer Epidemiol Biomarkers Prev 15: 536-542, 2006.

28. Chen M, Kamat AM, Huang M, et al: High-order interactions among genetic polymorphisms in nucleotide excision repair pathway genes and smoking in modulating bladder cancer risk. Carcinogenesis 28: 2160-2165, 2007.

29. Gangwar R, Mandhani A and Mittal RD: XPC gene variants: a risk factor for recurrence of urothelial bladder carcinoma in patients on BCG immunotherapy. J Cancer Res Clin Oncol 136: 779-786, 2010.

30. Khan SG, Muniz-Medina V, Shahlavi T, et al: The human XPC DNA repair gene: arrangement, splice site information content and influence of a single nucleotide polymorphism in a splice acceptor site on alternative splicing and function. Nucleic Acids Res 30: 3624-3631, 2002.

31. Pashos CL, Botteman MF, Laskin BL and Redaelli A: Bladder cancer: epidemiology, diagnosis, and management. Cancer Pract 10: 311-322, 2002.

32. Ross RK, Jones PA and Yu MC: Bladder cancer epidemiology and pathogenesis. Semin Oncol 23: 536-545, 1996.

33. Marcus PM, Hayes RB, Vineis P, et al: Cigarette smoking, $\mathrm{N}$-acetyltransferase 2 acetylation status, and bladder cancer risk: a case-series meta-analysis of a gene-environment interaction. Cancer Epidemiol Biomarkers Prev 9: 461-467, 2000.

34. Castelli EC, Mendes-Junior CT, Viana de Camargo JL and Donadi EA: HLA-G polymorphism and transitional cell carcinoma of the bladder in a Brazilian population. Tissue Antigens 72: 149-157, 2008.

35. Wu XR: Urothelial tumorigenesis: a tale of divergent pathways. Nat Rev Cancer 5: 713-725, 2005.

36. Yang J, Xu Z, Li J, et al: XPC epigenetic silence coupled with p53 alteration has a significant impact on bladder cancer outcome. J Urol 184: 336-343, 2010. 